\title{
Leadership Styles: Moderating Impact on Job Stress and Health
}

\author{
Saliha Gul Abbasi \\ Air University School of Management, Islamabad, Pakistan \\ salihagul.uajk@gmail.com \\ Received date: 11 January 2018; Accepted date:30 May 2018; Published date:07 July 2018. \\ Academic Editor: Khairunesa Isa \\ Copyright (C) 2018. Saliha Gul Abbasi .Distributed under Creative Commons CC-BY 4.0
}

\begin{abstract}
A straight relationship between stress and outcomes is well documented, but scarce studies adequately tested the range of mediated, moderated and additive effects of variables on outcomes that may strengthen or weaken this relationship. The present study based on Bass Model of Leadership, investigating the moderating impact of transformational and laissez-faire leadership on job stress and health relationship. The study also examines the predicting role of leadership and different role stressors with reference to health. The study was carried out on a randomly selected sample of 240 (88 males and 152 females) medical doctors. They were administered questionnaires including Multifactor Leadership Questionnaire (MLQ), Role Stress Inventory (RSI) and General Health Questionnaire (GHQ). Multiple hierarchical regression analyses revealed that transformational and laissez-faire leadership styles significantly moderate the relationship between stressors and health. Furthermore, multiple regression analyses indicated that role ambiguity and role conflict have significant impact on health, whereas, role overload showed no significant effect.
\end{abstract}

Keywords: Health, Laissez-faire leadership, Role stressors and Transformational leadership.

\section{Introduction}

The employees of the millennium appear to be more insecure, experience greater uncertainties and perceive work situations as more risky and threatening. At the same time, they are required to be rather more creative, innovative, flexible and teamorientated to accept business challenges and to do more with fewer resources. Consequently, stress appears to be increasing and emerges as one of the most pervasive

Cite this Article as: Saliha Gul Abbasi (2018)," Leadership Styles: Moderating Impact on Job Stress and Health", Journal of Human Resources Management Research, Vol. 2018 (2018), Article ID 322892, 
phenomena, adversely affecting the people. Stress has become a major concern not only to the individuals, but also to the organizations (Yamaguchi, Kim, Oshio \& Akutsu, 2017; Eddy, Wertheim, Kingsley \& Wright, 2017).

Literature identifies six basic environmental factors including demand, control, support, and relationship at work, roles and organizational change to have a potential impact on employees' well-being, ultimately leading to poor organizational outcomes (Mackay et al. 2004). Among these, role stressors are identified as common sources of work stress in the literature (Hill, Chênevert \& Poitras, 2015). Keeping in view the empirical, academic, theoretical and practical importance, the present study has focused on three important types of role stressors as explanatory variables; i.e. role ambiguity, role conflict and role overload.

Since the pioneering work of Kahn et al (1964) on organizational role dynamics, researchers have investigated the relationship between work role stressors and a variety of consequences such as job satisfaction, organizational commitment, job performance and turnover (Ngo, Foley \& Loi, 2005; Perrewe et al. 2004; Cai, Jia \& Li, 2016). Although, a good deal of research has examined the impact of stressors on job related outcomes but scarce research work has explored the impact of stressors on health (physical and mental) outcome (Jex \& Crossley, 2005; Yamaguchi et al. 2017). Furthermore, a direct or straight relationship between stress and outcomes has been established, few studies have adequately tested the range of mediated, moderated and additive effects of variables on outcomes that may strengthen or weaken this relationship (Ngo et al. 2005; Dragano et al. 2017).

The dominant role of leadership at workplace stress always remained critical (Yamaguchi et al. 2017). In empirical studies, leadership has been found to directly affect the role stressors, as lack of support from others at work, lack of encouragement by superiors and dealing with ambiguous or delicate situations (Loosemore \& Waters, 2004). Leaders or supervisors, being critical elements of organizational context, exert influence on subordinates' behaviors, need to be considered as a potential moderator for in-depth understanding of the workplace stress (Judge, Bono, Ilies, \& Gerhart, 2002; Smith \& Tonidandel, 2003; Kelloway, Sianathan, Francis \& Barling, 2005).

Consequent upon these reviews, the main focus of the present study is to examine the moderating role of transformational and laissez-faire leadership styles between role stressors and health outcome relationship.

\section{Literature Review}

Occupational stress encompasses the stress experienced at one's place of work, occupation or employment. The literature identified several sources of occupational stress e.g., task-based stress, role-based stress, environmental stress and social stress (Dollard, 2003). According to a comprehensive definition, work stress is harmful physical and emotional responses that occur when the requirements of the job do not match the capabilities, resources or needs of the worker. Suppressing feelings of stress and anger result in guilt, petulance and depression (Yamaguchi et al. 2017).

\section{Role Stressors}

Environmental stressors, regardless of the type or size of organization, include demands, control, support, work relationships, roles and organizational change. The studies have identified mainly the role ambiguity, conflict and overload that have potential for a negative impact on employee well-being (Mackay et al. 2004). Stress has been found to be associated with physical health (Yamaguchi et al. 2017).

Role ambiguity represents the uncertainty felt by a focal actor and occurs when an individual does not have clear or explicit information about the expectations of his or 
her role in the job or organization (Rizzo, House \& Lirtzman, 1970). Role conflict exists when two or more requirements of an employee's role are conflicting; that is, complying with one role requirement makes it difficult to comply with another (Rizzo et al. 1970). Role overload refers to the sheer amount of work required and a limited time frame in which work must be completed. Effort-reward imbalance (ERI) model of workplace stress explains how stress causes CVD, depression, absenteeism, smoking, alcoholism and their underlying mechanism (Eddy et al. 2017).

More specifically, role overload is caused by too much work, time pressures, deadlines and lack of personal resources needed to fulfill duties, commitments and responsibilities (Cooper, Dewe \& O'Driscoll, 2001). Expression of feelings reduces negative emotions and improves general well-being, physical health and reduces stress (Yamaguchi et al. 2017); transformational leadership through individualized consideration and idealized influence develops nurturing relation with others at workplace (Jyoti \& Bahu, 2016) that may reduce the negative impact of stressors on individuals' health.

Role stressors have been studied by researchers in different contexts and involving different population groups (Posig \& Kickul, 2003). Role stressors have been empirically investigated and linked to a variety of physiological, psychological and behavioral strain symptoms (Ngo et al. 2005; Perrewe et al. 2004; Yamaguchi et al. 2017) and prior research has shown higher levels of anxiety, depression and poor job performance (Eddy et al. 2017).

\section{Leadership}

Leadership encompasses everything from the first-level supervisor effects on subordinates' attitudes to the effects of CEOs on organizational performance; from the attribution processes to characterize leaders to the engagement of leaders' specific activities; and from the characteristics of people who emerge as leaders to the effects of actual leaders themselves (Judge et al. 2002; Ding et al. 2017). The ability to influence others is also a defining feature of leadership.

Leadership styles are relatively stable patterns of behavior displayed by leaders. After establishing the transactionaltransformational leadership paradigm, a more comprehensive leadership theory called the 'Full-Range Leadership Theory' (FRLT) was proposed by Avolio and Bass (1991). In the model, it is argued that other leadership models exhibit two-dimensional models of leaders' behavior, whereas, FRLT covers leadership styles more comprehensively by subsuming prior prominent models (Cai, Jia \& Li, 2016).

\section{Transformational Leadership}

Transformational leaders are proactive, inspire and motivate followers to achieve higher order goals, by influencing values, beliefs, attitudes and behaviors of followers (Giddens, 2017). Avolio and Bass (2002) identified distinct components of transformational leadership including; idealized influence, inspirational motivation, intellectual stimulation, and individualized consideration. Transformational leadership explains the underlying mechanisms that influence different outcomes (Ding et al. 2017)

For successful survival of organizations, committed and stress free human resources are an asset that is inimitable. To keep them motivated and engaged leaders play a distinctive role (Jyoti \& Bhau, 2016). Transformational leadership has been associated with high performance work teams, improved patient care and nurses' safety performance (Giddens, 2017). In addition to the direct impact of leadership on performance, affective organizational commitment and organizational citizenship behaviors, the relationship of transformational leadership and outcomes 
also has been examined being moderated by job enrichment, goal setting and the job characteristics, work engagement, turnover intention (Whittington Goodwin \& Murray 2004, Ding et al. 2017).

\section{Laissez-Faire Leadership}

Laissez-faire leadership represents the absence of a transaction of sorts with respect to leadership in which the leader avoids making decisions, abdicates responsibility and does not use the authority. As the French phrase implies, the laissez-faire leader takes a 'hands-off, let-things-ride' approach (Tarsik, Kassim \& Nasharuddin, 2014). In its more passive form, the leader either waits for problems to arise before taking action or takes no action at all and would be labeled passive-avoidant or laissez-faire. Such passive leaders avoid specifying agreements, clarifying expectations, goals and standards to be achieved by followers. Laissez-faire has been associated with negative outcomes like stress and demotivation (Yang, 2015).

Leadership has been consistently linked to a number of positive outcomes across cultural contexts and populations (Ding et al. 2017). However, few studies have considered the extent of the impact on negative organizational consequences (Zohar, 2002; Jyoti \& Bhau, 2016).

\section{Health}

According to medical experts there is a very strong link between stress and a person's health. Stress is described as a silent killer; because stress plays a major role in determining the physical and psychological health of an individual. Stress and depression are considered to be a serious public health problem as infectious diseases and AIDS (Eddy et al. 2017).

Higher level of stress is a major risk factor for poor health (Yamaguchi et al. 2017). Stress causes a variety of health problems in the individual; viz., physical, psychological and behavioral problems. Physical changes include heart diseases, stroke, gastrointestinal problems, respiratory disorders, sexual dysfunction, sleep disturbances and appetite disorders (Huczynski, 2001; Yamaguchi et al. 2017). The list of psychological changes includes experience of disorganized thinking, personality adjustment, hallucinations and delusions, emotional difficulties, depression as well as violent tendencies. The most common behavioral problems include burnout, drug and alcohol abuse, smoking, accident proneness and violence at work may ultimately lead to health problems (Piko, 2003). Workplace stress increases the risk of cardio vascular diseases by 50 percent (Eddy et al. 2017).

Research (De Dreu, Van Dierendonck, \& De Best-Waldhober, 2002) has indicated that role stressors are good predictors for individual well-being, physical and mental health at workplace, both in the short and long run. Studies examining physical health outcomes (Head, et al. 2002; Yamaguchi et al. 2017) found that high job demands, low decision latitude and effort reward imbalance were all related to increased incidence of heart diseases.

Supervisor behavior is perceived by many employees to have a significant influence on their health. Supervisor's support has a beneficial effect on worker performance and well-being and in some conceptualizations is seen to buffer the effects of stress on illhealth (Gilbreath \& Benson, 2004). Transformational leaders stimulate subordinates to deal with complex problems (Jyoti \& Bhau, 2016).

Leadership has been studied in direct relation to health (Kivimaki, et al. 2003) but relatively lacking those studies that have examined the moderating role of transformational and laissez- faire leadership styles in the stressors and health related outcome. 
Based on preceding literature review, the following hypotheses are developed:

H-1: The employees perceiving a higher level of role stressors will exhibit poor health.

H-2: Transformational leadership perception has a positive impact on health whereas, laissez-faire has a negative impact.

H-3: Transformational leadership perception will have a positive moderating effect on the relationship between role stressors and health.

H-4: Laissez-faire leadership perception will have a negative moderating effect on employees' reported role stressors and health relationship.

\section{Methods}

\section{Measures}

A structured questionnaire containing Role Stressor Inventory (RSI) adopted from Pareek (1983) was used to measure role stressors i.e. role ambiguity, role conflict and role overload rated on a five-point Likerttype scale $(1=$ Never to $5=$ =Always). The alpha coefficient value of role stressors was 0.85 .

The concept of health was measured by the General Health Questionnaire (GHQ), by Goldberg (1978). This is four-point response scale ranging from 1-4, with "Never" to "Very Frequently" responses respectively. The higher scores on this scale show poor health status, while lower scores show good health. The alpha coefficient value of health was 0.90 .

The short form leadership questionnaire, Multifactor Leadership Questionnaire (MLQ) by Bass and Avolio (1995) measured the transformational and laissez-faire leadership styles. Alpha reliability coefficients of transformational and laissez-faire leadership styles in the study were .92 and .88 respectively.

\section{Sample}

Keeping in view the importance and relevancy of the issue, the population selected in the present study was medical doctors. A sample of 240 doctors including 88 males (37\%) and 152 females (63\%), in different specialties of public sector hospitals of Islamabad and Rawalpindi, Pakistan, were selected, based on a simple random sampling design.

\section{Procedure}

The respondents were approached through the relevant administration. The purpose of the study was explained and the confidentiality of responses for individuals and the organizations were ensured. A total of 300 questionnaires were administered and 240 questionnaires completed in all respects were returned with $80 \%$ response rate.

\section{Data Analysis}

Multiple regressions analysis was applied to find out the impact of role stressors and leadership styles on health of individuals. Consistent with Eddy et al. (2017) a hierarchical multiple regression analysis was used to test the hypothesized moderating effects determining the additional variance i.e., beyond main effect, accounted for, by a leadership style. The change in $R^{2}\left(\Delta R^{2}\right)$ after the inclusion of the additional variable (interaction term) explains additional variance in the dependent variable. The presence of a moderating effect is shown by a corresponding change in $F$ with degree of freedom at the specified $p$ value. 


\section{Results}

Table 1: Correlations and Reliability $(\mathrm{N}=\mathbf{2 4 0})$

\begin{tabular}{|l|l|l|l|l|l|}
\hline & Variables & $\boldsymbol{I}$ & $\boldsymbol{I I}$ & $\boldsymbol{I I I}$ & $\boldsymbol{I} \boldsymbol{V}$ \\
\hline $\boldsymbol{I}$ & Role Stressors & .85 & & & \\
\hline $\boldsymbol{I I}$ & Transformational Leadership & $-.41^{* *}$ & .92 & & \\
\hline $\boldsymbol{I I I}$ & Laissez-faire Leadership & $.43^{* *}$ & $-.08^{*}$ & .88 & \\
\hline $\boldsymbol{I} \boldsymbol{V}$ & Health & $.63^{* *}$ & $-.42^{* *}$ & $.48^{* *}$ & .90 \\
\hline
\end{tabular}

$p<0.01 *, p<0.001 * *($ Reliability values are given on the diagonal $)$

The inter-correlation matrix in Table 1 shows that transformational leadership style has significant negative relation with role stressors $(r=-.41, \mathrm{p}<.001)$, health $(r=-.42$, $p<.001)$ and laissez-faire leadership style $(r$ $=-.08, \quad p<.01)$. Whereas, the laissez-faire leadership style shows significant positive correlations with role stressors $(r=.43$, $p<.001)$ and health $(r=.48, p<.001)$. The roles stressors are shown to have significant positive relation with health $(r=.63, \mathrm{p}<.001)$.

Table 2: Multiple Regression Analyses for Role Stressors and Leadership Styles with Health $(\mathrm{N}=\mathbf{2 4 0})$

\begin{tabular}{|l|l|l|l|l|l|}
\hline Dependent Variable & Independent Variables & $\boldsymbol{\beta}$ & $\boldsymbol{t}$ & $\boldsymbol{R}^{2}$ & $\boldsymbol{F}$ \\
\hline Health & Role Overload & .04 & .92 & & \\
\hline & Role Ambiguity & .23 & $3.55^{*}$ & .48 & $73.57^{* *}$ \\
\hline & Role Conflict & .49 & $8.02^{*}$ & & \\
\hline & $\begin{array}{l}\text { Transformational } \\
\text { Leadership }\end{array}$ & -.23 & $-3.31^{*}$ & .30 & $34.81^{* *}$ \\
\hline & Laissez-faire Leadership & .37 & $6.36^{* *}$ & & \\
\hline
\end{tabular}

$p<.01 *, p<0.001 * *$

The results of the multiple regression analyses in Table 2 show that role ambiguity and conflict have a significant impact on health, whereas role overload does not show a significant relationship. The value of $R^{2}=$ .48 shows that $48 \%$ of variance is explained by independent variables (role stressors) in the dependent variable (health) with $(F=$ $73.57, p<.001)$. Beta values of .23 $(p<.001)$ and $.49(p<.001)$ for role ambiguity and role conflict respectively show that role conflict contributes more among these variables to affect health.
Table 2 also shows that transformational and laissez-faire leadership styles have significant impact on health. The value of $R^{2}=$ .30 shows that $30 \%$ of variance is explained by leadership styles in health $(F=34.81$, $p<.001)$. Beta values of $-.23, p<.01$ and .37 , $p<.001$ for transformational leadership and laissez-faire leadership respectively, show that transformational style has a negative affect (lower score shows improved health), while laissez-faire has a positive impact on health. 
Table 3: Moderating Regression Equation (Transformational Leadership and Health) $\mathbf{N}=\mathbf{2 4 0}$

\begin{tabular}{|l|l|l|l|l|l|l|}
\hline Model & Variables & $\boldsymbol{B}$ & $\boldsymbol{t}$ & $\boldsymbol{F}$ & $\boldsymbol{R}^{\mathbf{2}}$ & $\boldsymbol{\Delta R}^{\mathbf{2}}$ \\
\hline I & Role Stressors & .43 & $7.41^{*}$ & & & \\
\hline & Transformational Leadership & -.44 & $5.89^{*}$ & 91.15 & .435 & \\
\hline II & $\begin{array}{l}\text { Role Stressors*Transformational } \\
\text { Leadership }\end{array}$ & .30 & $4.44^{*}$ & 72.24 & .479 & $.044^{*}$ \\
\hline
\end{tabular}

$p<0.001^{*}$

In Table 3 (change in the $R^{2}$ ) $\Delta R^{2}=.044$, with $(F=91.15, d f=1,236, \quad p<.001)$ shows additional variances of $4.4 \%$ in health. The values of Model-2 $(\beta=.30, \mathrm{p}<.001)$ show a significant moderating effect concluding slope difference.

Table 4: Moderating Regression Equation (Laissez-faire Leadership and Health) $\mathrm{N}=\mathbf{2 4 0}$

\begin{tabular}{|l|l|l|l|l|l|l|}
\hline Model & Variables & $\boldsymbol{\beta}$ & $\boldsymbol{t}$ & $\boldsymbol{F}$ & $\boldsymbol{R}^{\mathbf{2}}$ & $\boldsymbol{\Delta R}^{\mathbf{2}}$ \\
\hline I & Role Stressors & .47 & $8.68^{* *}$ & & & \\
\hline II & Laissez-faire Leadership & -.06 & -.58 & 98.43 & $.454^{* *}$ & \\
\hline $\begin{array}{l}\text { Role Stressors*Laissez-faire } \\
\text { Leadership }\end{array}$ & .37 & 3.02 & 09.13 & $.467^{*}$ & $.013^{*}$ \\
\hline
\end{tabular}

$p<0.001^{* *}, p<.01^{*}$

Table 4 shows $\Delta R^{2}=.013$, with $(F=9.13, d f=1$, $236, p<.01)$ explaining an additional variance of $1.3 \%$ in health with a significant moderating affect in Model-2 $(\beta=.37, p<.01)$.

\section{Discussion}

In the first hypothesis it was posited that employees perceiving higher level of role stressors would exhibit poor health. The results show that $48 \%$ of variance is explained by role stressors in health. The hypothesis is partially supported as, out of three role stressors, role conflict and ambiguity show a highly significant effect, while, role overload does not reveal significant impact. Transformational leadership is positively associated with work engagement and has a non-positive impact on negative consequences at workplace (Ding et al 2017). The findings are also in line with previous empirical studies by Eddy et al. (2017) showing that workplace stress is associated with increased risk of cardio vascular diseases and other health issues.
The second hypothesis anticipated that perception of transformational leadership style would have an ameliorating impact on physical and mental health, whereas perception of a laissez-faire style would have a deteriorating impact on health. In Table 2, the value of $\Delta R^{2}=.30$, explained $30 \%$ of variance by leadership styles in health $(F=$ $34.81, p<.001)$. The hypothesis is substantiated as transformational style shows a significant negative impact on the score or improvement in the health status, while laissez-faire style, on the other hand, shows a positive beta value, indicating that laissez-faire style has a deteriorating influence on the health status.

According to Cai et al (2017) the level of perception of leadership style can be judged just by assessing the wellbeing of the staff. The findings are consistent with previous reports by Ding et al (2017) providing clues that transformational leadership style has health improving effect. Transformational leadership has been found to decrease

Saliha Gul Abbasi (2018), Journal of Human Resources Management Research, DOI: $10.5171 / 2018.322892$ 
sickness rates from $20 \%$ to $7 \%$ in one year (Cai et al. 2017).

These results are also in line with findings that supervisory support, more than coworkers' or family and friends' support alleviate the deleterious effects of stress factors with regards to health. In previous studies, stress due to poor supervision (laissez-faire) has been shown to manifest poor physical and mental health Chaudhary and Javed (2012).

Hypotheses 3 and 4 conjecture to examine the moderating role of transformational and laissez-faire leadership styles on role stressors and health relationship. The hypotheses are supported as the transformational style explained an additional variance of $4.4 \%$ in the role stressor and health relationship, whereas, laissez-faire leadership style shows $\Delta R^{2}$ $=.013$, explaining additional variances of 1.3 $\%$ in health.

The hypothesized moderating role of transformational leadership is explained by the fact that supervisors who were perceived to frequently engage in positive behaviors reported better somatic and psychological health (Gilbreath \& Benson, 2004). The findings are also in line with previous research, showing that stress due to poor supervision (laissez-faire) manifests poor health outcomes and more health related problems (Skogstad, Einarsen, Torsheim, Aasland \& Hetland, 2007).

The endeavor would be useful, theoretically and practically, to both academia and practitioners. The study expands and advances conceptual knowledge on Bass Model of leadership, integrating leadership and occupational stress literature. The previous research mainly focused on direct relationship of job stress and outcomes, ignoring the impact of moderators. The current research enhances clarity and compensates the methodological flaws in stress and outcomes research. Additionally, the results also provide insight and awareness to management in policy making and to design training programs with reference to leadership, stress and employees' health.

\section{Theoretical and Practical Implications}

Role conflict and role ambiguity lead to poor health. Victims of role stressors will exhibit poor overall health. Managers, supervisors and other individuals in leadership roles should adopt transformational leadership style as it will improve the mental and physical health of subordinates in comparison to Laissez-faire style that has a detrimental effect on health.

To improve the health score of individuals at workplace, transformational leadership is the preferred style. Transformational leadership style will help to reduce the negative impact of role stressors, i.e., role conflict and role ambiguity on general health conditions of employees, whereas in case of Laisezz-faire style, impact would be the opposite and deteriorating.

It further suggests that work load, time pressure, lack of responsibility and deadlines do not negatively affect health and do not lead to burnout. However, lack of information about what and how to perform and contradictory expectations from an individual are one of the causes of poor health.

\section{Limitations and Future Research}

Though, current study contributes to basic knowledge of stress, leadership and health, still few limitations were there, suggesting future research areas. Leadership and stress being the universal phenomena, the validation of the current findings may be sought by examining employees from other professionals, culturally diverse organizations and a cross-cultural replication of the current study.

The study relied solely on subordinates' selfreported measures of variables. The ratings from a single subordinate in some cases may not be the best judges of supervisors' 
behavior. The aspects like, subordinate, peers and seniors should be considered while commenting on supervisor's behavior.

Although, role conflict, overload and ambiguity have been well substantiated as key stressors in organizations, it is recommended for future studies to examine a broader set of job stressors to demonstrate moderating effects.

In addition, some factors that may affect the subjective perception of stress in the workplace, including individual personality variables, organizational and cultural variables, are factors requiring worth exploring in future research. Another limitation of the present study was the crosssectional study design. A longitudinal design would capture more dynamic nature of the stress process and consequences.

\section{References}

1. Avolio, BJ. and Bass, BM. (1991), 'The full range leadership development programs: basic and advanced manuals', Binghamton, NY: Bass, Avolio \& Associates.

2. Avolio, BJ. and Bass, BM. (2002), 'Manual for the Multifactor Leadership Questionnaire (Form 5X)', Redwood City, CA: Mindgarden.

3. Bass, MB. and Avolio, JB. (1995), 'The multifactor leadership questionnaire leader form 5-x-short', Palo Alto, CA: Mind Garden.

4. Bass, BM. (1997), 'Does the transactionaltransformational leadership paradigm transcend organizational and national boundaries?', American Psychologist, 52, 130 139.

5. Dragano, N., Siegrist, J., Nyberg, ST., Lunau, T., Fransson, EI., Alfredsson, L. and Bjorner, JB. (2017), 'Effort-reward imbalance at work and incident coronary heart disease: A multicohort study of 90,164 individuals', Epidemiology, 28, 619-626.
6. Cai, Y., Jia, L. and Li, J. (2017), 'Dual-level transformational leadership and team information elaboration: The mediating role of relationship conflict and moderating role of middle way thinking', Asia Pacific Journal of Management, 34(2), 399-421.

7. Chaudhry, AQ and Javed, H. (2012), 'Impact of Transactional and Laissez Faire Leadership Style on Motivation', International Journal of Business and Social Science, 3(7), 258-264.

8. Clegg, A. (2001), 'Occupational stress in nursing: a review of the literature', Journal of Nursing Management, 9, 101-106.

9. Cooper, CL., Dewe, PJ. and O'Driscoll, MP. (2001), 'Organizational stress: A review and critique of theory, research, and applications', Thousands Oaks, CA; Sage.

10.De Dreu, CKW., Van Dierendonck, D. and De Best-Waldhober, M. (2002), 'Conflict at work and individual wellbeing. In $M$. Schabracq, JAM. Winnubst, \& CL. Cooper (Eds.), The handbook of work and health psychology. Chichester, UK: Wiley.

11.Ding, X., Li, Q., Zhang, H., Sheng, Z. and Wang, Z., (2017), 'Linking transformational leadership and work outcomes in temporary organizations: A social identity approach', International Journal of Project Management, $35,543-556$.

12.Dollard, M.F. (2003), 'Introduction: Context theories and intervention', In MF. Dollard, AH. Winefield and HR. Winefield (Eds.), Occupational stress in the service professions. New York: Taylor \& Francis.

13.Eddy, P., Wertheim, EH., Kingsley, M. and Wright, B J. (2017), 'Associations between the Effort-Reward Imbalance model of workplace stress and indices of cardiovascular health: a systematic review and meta-analysis', Neuroscience and Biobehavioral Reviews, https://doi.org/10.1016/j.neubiorev.2017.1 0.025 .

Saliha Gul Abbasi (2018), Journal of Human Resources Management Research, DOI: $10.5171 / 2018.322892$ 
14.Epitropaki, O. and Martin, R. (2005), 'The moderating role of individual differences in the relation between transformational/transactional leadership perceptions and organizational identification', The Leadership Quarterly 16, 569-589.

15.Giddens, J. (2017), 'Transformational leadership: What every nursing dean should know', Journal of Professional Nursing, doi:10.1016/j.profnurs.2017.10.004, Accessed 20 November, 2017.

16.Gilbreath B. and Benson PG. (2004), 'The contribution of supervisor behavior to employee psychological well-being', Work \& Stress, 18, 255-266.

17.Goldberg, D. (1978), 'Guide to the General Health Questionnaire', Nelson publishing company, Windsor Berks.

18.Greenberg, J. and Baron, AR. (2003), 'Behavior in organizations', New Jersey, Prentice Hall International, Inc.

19.Head, J., Martikainen, P., Kumari, M., Kuper, H. and Marmot, M. (2002), 'Work environment, alcohol consumption and ill health: The Whitehall 2 Study', HSE Contract Research Report 422/2002. Sudbury: HSE Books.

20.Hill, K., Chênevert, D. and Poitras, J. (2015), 'Changes in relationship conflict as a mediator of the longitudinal relationship between changes in role ambiguity and turnover intentions', International Journal of Conflict Management, 26(1), 44 - 67.

21.House, JS. (1981), 'Work stress and social support', Reading, MA: Addison-Wesley.

22.Huczynski, A. and Buchanan, D. (2001), 'Organizational Behavior', Prentice Hall.

23.Jex SM. and Crossley CD. (2005), 'Organizational Consequences', In Handbook of work stress (p. 575-599). California: Sage Publications, Inc.
24.Judge, TA., Bono, JE., Ilies, R. and Gerhardt, MW. (2002), 'Personality and leadership: A qualitative and quantitative review', Journal of Applied Psychology, 87, 765-780.

25.Jyoti, J. and Bhau, S. (2016), 'Empirical investigation of moderating and mediating variables in between transformational leadership and related outcomes: A study of higher education sector in North India', International Journal of Educational Management ,30(6), 1123-1149.

26.Kahn, R., Wolfe, R., Quinn, R., Snoek, J. and Rosenthal, R. (1964), 'Organizational stress: Studies in role conflict and ambiguity', New York: Wiley.

27.Kark, R. and Shamir, B. (2002), 'The influence of transformational leadership on followers' relational versus collective selfconcept', Academy of Management Proceedings, OB: D1-D6.

28.Kelloway, EK., Sivanathan N., Francis L. and Barling, J. (2005), 'Poor leadership', In Handbook of work stress (pp. 89-112), Sage Publications, Inc, Thousand Oaks, California.

29.Kivimaki, M., Virtanen, M., Vartia, M., Elovainio, M., Vahtera, J. and Keltikangas Jarvinen, L. (2003), 'Workplace bullying and the risk of cardiovascular disease and depression', Occupational and Environmental Medicine, 60, 779-783.

30.Le Fevre, M., Matheny, J. and Kolt, G. (2003), ' Eustress, distress, interpretation in occupational stress', Journal of Managerial Psychology, 18, 726-744.

31.Loosemore1, M. and Waters, T. (2004), 'Gender Differences in Occupational Stress Among Professionals in the Construction Industry', Journal of Management in Engineering, 26, 126-132.

32.Mackay, CJ., Cousins, R., Kelly, PJ., Lee, S. and Mccaig, RH. (2004), 'Management Standards' and work-related stress in the UK:

Saliha Gul Abbasi (2018), Journal of Human Resources Management Research, DOI: $10.5171 / 2018.322892$ 
Policy background and science, Work \& Stress, 18, 91-112.

33.Ngo, HY., Foley, S. and Loi, R. (2005), 'Work role stressors and turnover intentions: a study of professional clergy in Hong Kong', Journal of Human Resource Management, 16, 2133-2146.

34. Pareek, U. (1983), Role stress scale, Naveen Publications: Ahmedabad, India.

35.Perrewe, PL., Zellars, KL., Ferris, GR., Rossi, AM., Kacmar. CJ., Ralston, DA. (2004), 'Neutralizing Job Stressors: Political Skill as an Antidote to the Dysfunctional Consequences of Role Conflict', Academy of Management Journal, 1, 141-152.

36.Peter, GN. (2007), 'Leadership: Theory and Practice', Western Michigan University, Los Angeles, Sage Publications Inc.

37.Piko, BF. (2003), 'Psychosocial work environment and psychosomatic health of nurses in Hungary', Work \& Stress, 17, 93100.

38. Posig, M. and Kickul, J. (2003), 'Extending our understanding of burnout: Test of an integrated model in non-service occupations', Journal of Occupational Health Psychology, 8, 3-19.

39. Revicki, DA., Whitley, TW., Gallery, ME. and Allison, EJ. (1993), 'The impact of work environment characteristics on work-related stress and depression in emergency medical residents: a longitudinal study', Journal of Community Applied Social Psychology, 3, 273284.

40.Rizzo, J., House, RJ. and Lirtzman, SI. (1970), 'Role Conflict and Ambiguity in Complex Organizations', Administrative Science Quarterly, 15, 150-63.

41.Shin, S, J. and Zhou, J. (2003), 'Transformational leadership, conservation, and creativity: Evidence from Korea', The
Academy of Management Journal, 46, 703714.

42.Smith, D.B. and Tonidandel, S. (2003), 'Taking account of time: The application of event history analysis to leadership research', Leadership Quarterly, 14, 241-256.

43.Tarsik, NF, Kassim, NA. and Nasharuddin, N. (2014), 'Transformational, Transactional or Laissez-Faire: What Styles do University Librarians Practice?', Journal of Organizational Management Studies, 20(14), 1-10.

44.Townsend, J., Phillips, J.S. and Elkins, T.J. (2000), 'Employee retaliation: the neglected consequence of poor leader-member exchange relations', Journal of Occupational Health Psychology, 5, 457-63.

45.Wager, N., Feildman, G. and Hussey, T. (2003), 'The effect on ambulatory blood pressure of working under favorably and unfavorably perceived supervisor', Occupational and Environmental Medicine, $60,468-474$.

46.Whittington, J. L., Goodwin, V. L. and Murray, B. (2004), 'Transformational leadership, goal difficulty, and job design: Independent and interactive effects on employee outcomes', The Leadership Quarterly, 15, 593-606.

47. Yang, I. (2015), 'Positive effects of laissezfaire leadership: conceptual exploration', Journal of Management Development, 34(10), 1-28.

48. Yamaguchi, A., Kim, M.S., Oshio, A. and Akutsu, S. (2017), 'The role of anger regulation on perceived stress status and physical health', Personality and Individual Differences. 116, 240-245.

49. Zohar, D. (2002), 'The effects of leadership dimensions, safety climate, and assigned priorities on minor injuries in work groups', Journal of Organizational Behavior, 23, 75-92.

Saliha Gul Abbasi (2018), Journal of Human Resources Management Research, DOI: $10.5171 / 2018.322892$ 